Broft, R.D. and Pryke, S. (2019). "A Supply Chain Rhythm: Multidisciplinary Teams Through Collaborative Work Structuring." In: Proc. 27 $7^{\text {th }}$ Annual Conference of the International. Group for Lean Construction (IGLC), Pasquire C. and Hamzeh F.R. (ed.), Dublin, Ireland, pp. 1261-1270. DOI: https://doi.org/10.24928/2019/0272. Available at: 〈www.iglc.net>.

\title{
SUPPLY CHAIN RHYTHM: MULTIDISCIPLINARY TEAMS THROUGH COLLABORATIVE WORK STRUCTURING
}

\author{
Rafaella D. Broft ${ }^{1}$ and Stephen Pryke ${ }^{2}$
}

\begin{abstract}
Collaborative work structuring methods are increasingly used in the construction industry to support project teams on delivering their projects on time, within budget and with high quality. By breaking down the work to be done in so-called manageable chunks, work structuring plays an important role in the creation of flow.

The optimisation of flow is important due to the fragmented nature of the industry. Despite successful examples of the application of these methods, it is believed that the advantages remain limited to achieving better project results. Where current examples organise working packages around the work of different trades, this paper explores the consequences of a more supply chain-driven approach to collaborative work structuring. It challenges trades to design a "Supply Chain Rhythm". The results presented in this paper show additional advantages, where multidisciplinairy teams have been created within a project. This way, the configuration of the crew performing the work chunk exceeds the boundaries of organisations or trades, and leads to further optimisation of the work flow.
\end{abstract}

\section{KEYWORDS}

Production system design, work structuring, collaboration, multidisciplinary teams, supply chain rhythm.

\section{INTRODUCTION}

Planning tools are increasingly used in the construction industry to support project teams on delivering their projects on time, within budget and with high quality. These tools relate to production system design and specifically to work structuring, and can be interlinked with other lean concepts, such as standardisation, continuous flow and predictability. They are considered transparent and more collaborative than most traditional methods used in the management of projects.

1 PhD Candidate, University College London, The Bartlett School of Construction \& Project Management, London, United Kingdom, r.d.broft@gmail.com

2 Professor, University College London, The Bartlett School of Construction \& Project Management, London, United Kingdom, s.pryke@ucl.ac.uk 
Work structuring is considered important in optimising work flow. It breaks down the work to be done in so-called chunks - where work structuring methods used to focus on the activity, more and more work structuring methods, such as Line of Balance, Flowline and planning with the use of a 'Takt' (Takt is a design parameter used for production in manufacturing), consider the location or location units as leading.

Alignment of the different activities (within the different units) of a construction process and the creation of flow seem important because of the fragmented nature of the industry. Despite successful examples of the application of these methods, it is believed that the advantages remain limited to achieving better project results. Currently, in order to minimise the costs of each subprocess, focus exists on the efficiency of every supplier's process and competitive pricing (Broft \& Koskela, 2018). Or in other words, every organisation or trade tends to focus on the efficiency of their own sub-process, leading to more specialised tasks and subsequently, prefabrication or off-site production as part of these tasks. In current examples of collaborative work structuring work packages are created around the (efficient) work of different trades.

This paper explores the consequences of a more supply chain-driven approach to collaborative work structuring. It describes an intervention, referred to as the design of a "Supply Chain Rhythm", that is collaboratively created with the members of a construction supply chain and applied to a first project.

The paper starts by describing the research context and by providing the reader with a short theoretical background. Hereafter, the intervention, the case study and the results are presented.

\section{RESEARCH CONTEXT}

As part of a long-term expert programme on SCM in construction, suppliers have been carefully selected for executing work for a particular type of projects. In other words, and in this particular case, all housing projects within the main contractor's portfolio are pursued with the same team of organisations.

The overall aim of the programme is to improve collaboration and subsequently, the competitive position of the construction supply chain gradually with every project. At this point of time, all members involved are aware of basic lean principles, project-oriented tools and driven to explore more opportunities for improving processes. This paper focuses on one of the interventions within the programme, aiming for the design of a collaborative production system with the help of a "Supply Chain Rhythm". This research is also part of a $\mathrm{PhD}$ research.

\section{THEORETICAL BACKGROUND}

\section{Production SYSTEM DESIGN}

Production system design (PSD) is one of three core activities - design, operation and improvement - of production management (Koskela \& Ballard, 2003). Alternatives of production organisation are studied in order to select the most appropriate strategy for achieving the desired results (Meredith \& Shafer, 2009), for both designing and making 
products. This intended production strategy needs to be translated into a set of decisions, which define the structure for managing the different activities and create appropriate conditions for control and improvement (Schramm et al., 2006). Askin and Goldberg (2002) state that PSD involves managing production resources in order to meet customer demands.

\section{PRODUCTION SYSTEM DESIGN IN CONSTRUCTION}

In construction, main contractors are contractually responsible for the construction of projects, but following from the high percentage of subcontracting, they rely on suppliers to execute the works (Clarke \& Herrmann, 2004). Main contractors are involved to organise and coordinate operations (Akintan \& Morledge, 2013) and subsequently, have a central position in managing construction (Broft \& Pryke, 2016). Besides site production, this includes a focus on managing the organisations or trades that deliver or produce services/materials on-site, or in other words, managing production.

In operational terms, the aim is to create favourable conditions for a highly performing production system by devising the construction layout, and material and information flows (Schramm et al., 2006). For a long time, theories regarding production management and production management practices as known in the 'highly productive and fast operating' repetitive manufacturing - high technological standards, rapidly changing demands and intense (global) competition have pressed these industries to manage processes throughout the supply chain in an effective and efficient way (Cagliano et al., 2006) - have been, both successfully or unsuccessfully, transferred to construction.

PSD is believed to be important for achieving the most important project goals, while it also represents the most basic form and opportunity for minimising the effect of variability on production (Ballard et al. 2001). According to Koskela (2000), the design of production systems has three main goals in construction: 1) deliver the project, 2) maximise value, and 3) minimise waste. PSD should take place before the execution phase in order to provide the project team with an overview of alternatives for production organisation including consequences for budget, time, and workflow (Biotto et al., 2017). It reaches from global organisation to the specific design of operations, i.e., from decisions regarding who is to be involved in what roles to decisions regarding how the physical work will be accomplished. One of the PSD outputs is a master plan that will be used once operation of the system starts (Schramm et al. 2004), also referred to as phase scheduling. Phase scheduling is a design activity used to structure each project phase and to produce a collaborative plan for completing it (Ballard et al., 2001). With this, the project team will be able to adapt the production system in case of any variabilities or uncertainties, minimising effects on production (Biotto et al., 2017). Work structuring is then used to break down phase activities into specific processes and operations, and to define the handoffs between trades, crews of sequential activities and the different project phases.

\section{WORK STRUCTURING}

While production system design focuses on the set of strategic decisions on a project's viability, budget and lead time, phase scheduling focuses on a clear definition of phase activities and its lead times, and work structuring on breaking down the work to be done in work chunks, hand-offs and production units, and the creation of flow (Biotto et al., 2017). 
The three important concepts in work structuring (Tsao, 2005) include:

- Production unit - "a group of production workers that do or share responsibility for similar work, drawing on the same skills and techniques";

- Work chunk - "a unit of work that can be handed off from one production unit to the next";

- Hand-off - "the combined (1) completion of a work chunk by a production unit that allows a subsequent production unit to further transform the work chunk or execute a different work chunk as planned, (2) declaration of completion of the work chunk by the production unit and release to the subsequent production unit, and (3) acceptance of the released work by the subsequent production unit".

In other words, work structuring breaks down both the product and the process into parts, sequences and assignments to realise (improvement of the) work flow, by reducing variability and waste, while increasing the value (Ballard, 1999). These so-called work chunks become more manageable. Each chunk includes work of a certain scope that will be performed by a crew of a certain configuration (number of crew members with their individual and combined skills), using certain means and methods (Tommelein, 2017).

\section{WORK STRUCTURING METHODS}

Different types of work structuring methods exist. Some of these are activity based planning tools, such as the Critical Path Method and PERT, whereas others are location based planning tools, such as Line of Balance, Flowline and planning with the use of a 'Takt'. The latter have originally been developed in manufacturing and adapted for construction by changing the vertical axis unit: location or zones instead of units produced (Kenley \& Seppänen 2010). This is a result of the differences that exist between the industries as in construction the work stations, or resources, move through the product to be delivered (Broft \& Koskela, 2018).

\section{INTERVENTION}

Work structuring is considered important in optimising work flow and therefore, considered a relevant step for growth in supply chain maturity (Broft et al., 2016), which is the overall aim of the expert programme. This paper describes an intervention, referred to as the design of a "Supply Chain Rhythm", that is case-specific and practice-based, created by the researcher in collaboration with different stakeholders involved in the project team. An additional drive for the supply chain to engage in this intervention was the limited availability of worker capacity, which is a result of the growing market. It was believed that optimisation could solve this extra problem.

\section{SUPPLY CHAIN RHYTHM}

In production management, 'Takt' refers to the regularity with which something gets done. It is "the unit of time within which a product must be produced (supply rate) in order to match the rate at which that product is needed (demand rate)" (Hopp \& Spearman, 2011, pp. 467-468), or in other words: Takt time = available net working time / customer demand in that time. Rhythm is defined as "a strong, regular repeated pattern of movement or sound" 
or "a regularly recurring sequence of events or processes" (Oxford dictionary, 2019). In music, rhythm refers to the variety of tones of different duration. It is a repetition of something equivalent within comparable units (Müller \& Enskat, 1973), so-called rhythmic units. A rhythmic unit is a durational pattern (where its duration is related to its tempo) that synchronises with a pulse or Takt (Winold, 1975).

A rhythm thus encompasses Takt, a regularity of its content and a distrubition of its time. In construction, the objective of takt planning has been to provide a balanced work flow for trades (Frandson \& Tommelein, 2016) to increase productivity and shorten the overall lead time (Heinonen \& Seppänen, 2016). Supply chain rhythm goes beyond existing patterns of individual organisations or trades and refers to collaboratively composed patterns: "... all use the ability of rhythm to unite human individuals into a shared collective identity where group members put the interests of the group above their individual interests and safety..." (Jordania, 2011). The difference made in this paper exists to indicate a certain freedom, within a regularity, providing a supply chain with freedom to adapt its work content, to move work within work packages and to allow changes in tasks, within a set time frame. A rhythm is believed to invite movement. "Once one becomes consequent in its rhythm, one can start working on the speed."

\section{CASE STUDY DESCRIPTION}

The project team comprises suppliers with a long-term collaboration (which means all of them had previously worked together on other projects for the same main contractor) around the construction of houses in the Netherlands.

The case study that was selected for this specific research comprises a total of 21 houses - two blocks that are part of a bigger project (Figure 1). Together with representatives of all the organisations involved (five organisations representing six trades), one of the authors had focused on the design of an alternative production system to deliver this part of the project. The execution, including on- and off-site production, and logistics to site were then based on this PSD.

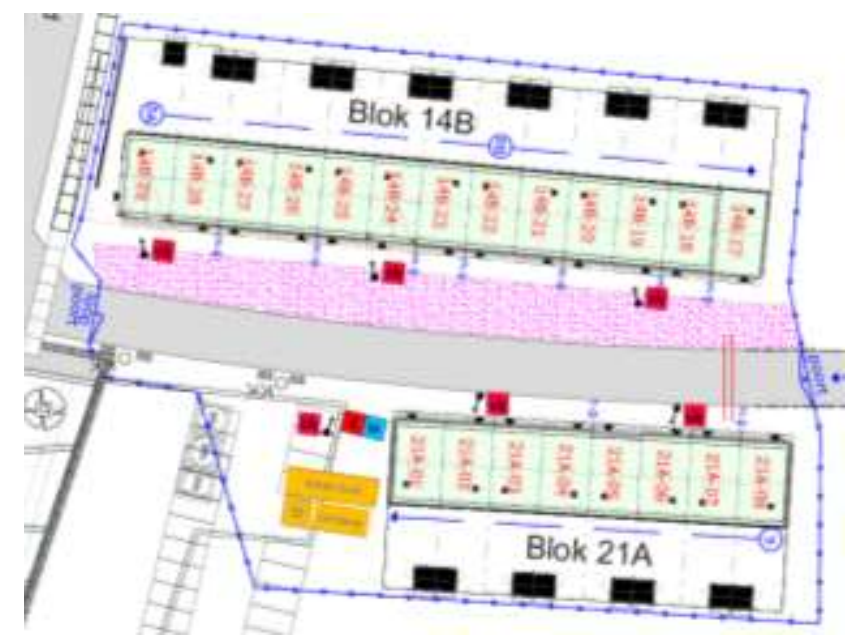

Figure 1: Case study - site plan including the 21 houses. 


\section{APPROACH}

The intervention aims to explore the consequences of collaborative production system design, and specifically collaborative work structuring that is supply-chain driven. As part of this work structuring process different sessions were organised. The first question involved: At what speed should the 'production line' progress? Or in other words, what is the duration of a rhythmic unit? Previous measurements provided the supply chain with information on how to choose an appropriate speed. Based on this information and some further research, the five organisations involved decided on this speed/duration and the 'Takt' (which includes information on the boundary of zones). The content - work sequence, packaging of the tasks and the different hand-offs - was established during next sessions, first more generally using a template, then applied specifically to this first project.

This 'rhythm', including a detailed plan for the project, was the starting point for all the preparations necessary for successful execution, i.e. logistics based on the agreed zones, adapted coordination of all material suppliers and the careful involvement of site members. All work had to be done with restricted site access. Because of this an hourly plan for the logistics had to be added to avoid stagnation of deliveries. At the start of the project a kickoff was organised on-site to be sure to include all site members and provide them with the basic information. Daily and weekly stands were organised to monitor the process.

As part of the research, structured interviews were held with all the members on-site, before and after implemention of the changes. Moreover, direct observations were registered of all the activities being executed on-site. To increase the involvement of all workers on-site, recommendations for improvement were collected.

\section{RESULTS \& ANALYSIS}

Every organisation has established a standard process for executing work on housing projects. This work involves a similar content and sequence from project to project. The results presented here show the changes in the overall sequence of the work - following from the new work structure, this has changed from horizontal to diagonal production (Figure 2a), which is a direct result of the location-based focus where the aim had been set to deliver one zone per a set amount of hours. Besides advantages in lead time - a reduction of 12 days (38 instead of 50 working days) - site members have mentioned other advantages, such as less inventory waiting for the next activity, the efficient use of the same crane, an increased reliability of planned work and people taking better account of others. These advantages have been classified: some can be related to collaborative work structuring in general, others seem specific to the intervention (as will be pointed out later).

All the activities per member have been registered providing the team with detailed information on work packages and work sequence, including a total of activities and hours per zone (Figure 2b). After analysis, differences between what had been originally planned versus realised through the collaborative work structuring method - a percentage of $51 \%$ had been achieved - became visible, giving input for re-design of the production system for future projects.

Moreover, the exact configuration of the project crew in a situation following the intervention, presented as the case, could be analysed through time. 


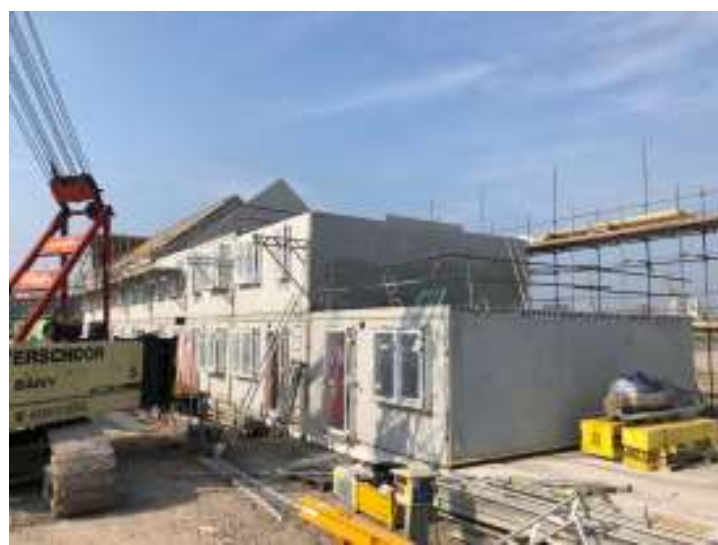

Figure 2a: Impression of site activities.

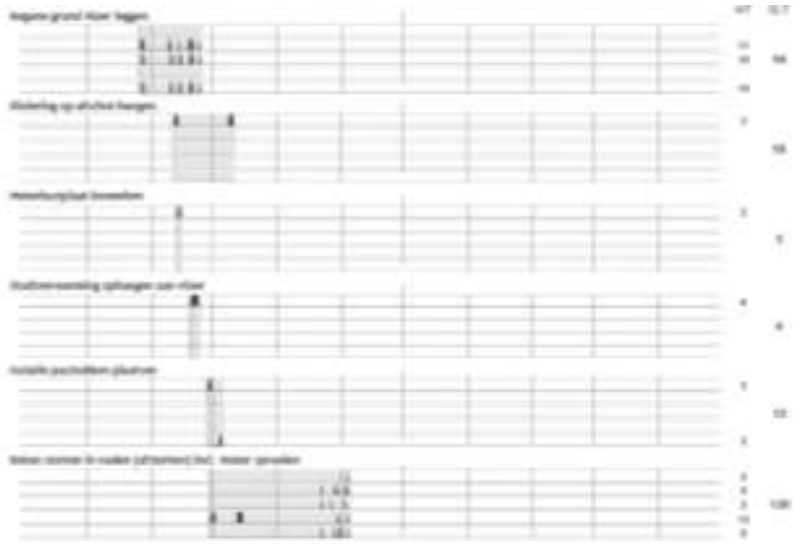

2b: Impression of the registration of activities.

The results presented in Table 1 show that in a 'situation-as-is' usually 15 members from five different organisations, representing six different disciplines or trades, show up onsite. During the sessions the team established to involve 13 members organised in three consecutive teams, whereas, during execution, this amount reduced further to 11 members (this change is shown with the two numbers presented in the third column).

Table 1: Structure of teams

\begin{tabular}{lcccc}
\hline Organisation & $\begin{array}{c}\text { \# Members on-site } \\
\text { (Usually) }\end{array}$ & $\begin{array}{c}\text { \# Members on-site } \\
\text { (Case study) }\end{array}$ & Team \\
\hline Organisation A & 5 & 4 & 4 & $\mathrm{I}$ \\
Organisation B & 2 & 2 & 1 & $\mathrm{I}$ \\
Organisation C & 2 & 2 & 2 & $\mathrm{II}$ \\
& 2 & 1 & 1 & $\mathrm{II}$ \\
Organisation D & 2 & 2 & 2 & $\mathrm{III}$ \\
Organisation X & 2 & 2 & 1 & $\mathrm{III}$ \\
\hline
\end{tabular}

Team I includes 5 members from organisation A and B, team II includes 3 members from two different departments of organisation $\mathrm{C}$, and team III includes 3 members of organisation D and X. This way, three multidisciplinary teams have been created, all encompassing at least two trades. The activity registration shows the amount of times that members supported each other on tasks and/or took over tasks from each other - members from organisation A and B have both supported each other, one department of organisation $\mathrm{C}$ has supported the other department, and organisation $\mathrm{D}$ has supported organisation $\mathrm{X}$ with their tasks. This seems to be a result of the increasing 'interdependency' which some have mentioned to have increased.

With the interviews, all site members involved had a chance to express their thoughts and ideas. More than 100 recommendations for improvement have been collected, of which some have been incorporated directly for the zones or houses still to be built. The collaboration on site had been valued by most members by a ' + ' with the reason that the 
atmosphere on site is pleasant and good. A few of them have been critical stating that there is still room for improvement, i.e. "Not everyone seems to be used to this way of building. Some remain stuck on their little island, while a bit more collaboration is needed".

\section{CONCLUSIONS}

Different (successful) applications of work structuring methods have been described before. Despite successful examples of the application of these methods, it was believed that the advantages remain limited to achieving better project results. Where current examples organise working packages around the work of different trades, this paper has explored the consequences of a more supply chain-driven approach to collaborative work structuring. It challenges trades to design a "Supply Chain Rhythm". The results presented in this paper show additional advantages, where multidisciplinairy teams have been created within a project. This way, the configuration of the crew performing the work chunk exceeds the boundaries of organisations or trades, moving away from further specialisation and fragmentation, and shows a possible step in further optimisation of the work flow. Not just by combining steps into working packages, but by transferring tasks to other organisations. Instead of a "Parade of Trades" (Tommelein et al., 1999) a "Parade of Teams" is created moving through space with one team following the other in sequence, all marching to a drum beat, and - ideally - with no variability.

The results presented here are limited to one project and therefore, case-specific. Further research is being done on practical validity and generalisability - in other words, further evaluation based on different type of projects, and design loops need to be done. As mentioned before, the results of this paper are part of a $\mathrm{PhD}$ research.

\section{ACKNOWLEDGEMENTS}

To acknowledge the second author of this paper - I would like to thank Prof. Stephen Pryke for his support and believe in my research, in any possible way. Always.

\section{REFERENCES}

Akintan, O.A. and Morledge, R. (2013), "Improving the collaboration between main contractors and subcontractors within Traditional Construction Procurement", Journal of Construction Engineering, Article ID 281236.

Askin, R. G. and Goldberg, J. B. (2002), Design and Analysis of Lean Production Systems, John Wiley.

Ballard, G. (1999), Work structuring, White Paper, Lean Construction Institute, Las Vegas.

Ballard, G., Koskela, L., Howell, G. and Zabelle, T. (2001), "Production system design in construction", in: Proceedings of the $9^{\text {th }}$ Annual Conference of IGLC.

Biotto C., Kagioglou M., Koskela L., and Tzortzopoulos P. (2017), "Comparing Production Design Activities and Location-Based Planning Tools", in: Proceedings of the 25th Annual Conference of IGLC, Heraklion, Greece, pp. 705-712.

Broft, R.D., and Koskela, L. (2018). "Supply Chain Management in Construction from a Production Theory Perspective", in: Proc. $26^{\text {th }}$ Annual Conference of IGLC, González, V.A. (ed.), Chennai, India, pp. 271-281. 
Broft, R.D. and Pryke, S. (2016), "Who should be leading in the implementation of SCM in construction?, in: Proceedings of the CIB World Building Congress 2016, Vol. I, Kähkönen, K. and Keinänen, M. (eds), Tampere, Finland, pp. 575-588.

Broft, R.D., S. Badi and Pryke, S. (2016), "Towards Supply Chain Maturity in Construction", Built Environment Project and Asset Management, Emerald, Special Issue.

Cagliano, R., Caniato, F. and Spina, G. (2006), "The linkage between supply chain integration and manufacturing improvement programmes", International Journal of Operations and Production Management, Vol. 26, No. 3, pp. 282-299.

Clarke, L. and Herrmann, G. (2004), "Cost vs. production: disparities in social housing construction in Britain and Germany", Construction Management and Economics, Vol. 22, No. 5, pp. 521-532.

Frandson, A. and Tommelein, I.D. (2016), "Development of a Takt-time Plan: A Case Study”, ASCE, in: Proceedings Construction Research Congres, Atlanta, GA, pp. 1646-1655.

Heinonen, A. and Seppänen, O. (2016), "Takt Time Planning”, in: Proceedings of the $24^{\text {th }}$ Annual Conference of IGLC.

Hopp, W.J. and Spearman, M.L. (2011), Factory Physics, $3^{\text {rd }}$ edition, Waveland Press, Inc., Long Grove.

Jordania, J. (2011), "Why do People Sing? Music in Human Evolution”, in: Tbilisi, Logos, International Research Center for Traditional Polyphony, The University of Melbourne.

Kenley, R. and Seppänen, O. (2010), Location-based management for construction: planning, scheduling and control, Spon, London.

Koskela, L. (2000), An exploration towards a production theory and its application to construction, VTT Publications, Finland.

Koskela, L. and Ballard, G. (2003), "What should we require from a production system in construction", in: Proceedings ASCE Construction Research Congress, pp. 19-21.

Meredith, J. R. and Shafer, S. M. (2009), Operations management for MBAs, John Wiley $\&$ Sons.

Müller, W. H., \& Enskat, A. (1973), Graphologische diagnostik, Huber.

Oxford dictionary (2019), https://en.oxforddictionaries.com/definition/rhythm.

Schramm, F. K., Costa, D. B., and Formoso, C. T. (2004), "The Design of Production Systems for Low-Income Housing Projects", in: Proceedings of the 12th Annual Conference of IGLC.

Schramm, F.K., Rodrigues, A.A. and Formoso, C.T. (2006), "The Role of Production System Design in the Management of Complex Projects", in: Proceedings of the 14th Annual Conference of IGLC, Santiago, Chile, pp. 227-239.

Tommelein, I.D. (2017), "Collaborative Takt Time Planning of Non-Repetitive Work", in: Proceedings of the 25th Annual Conference of IGLC, Heraklion, Greece, pp. 745752.

Tsao, C. C. (2005), Use of work structuring to increase performance of project-based production systems, $\mathrm{PhD}$ thesis, University of California, Berkeley.

Winold, A. (1975), "Rhythm in Twentieth-Century Music", in: Aspects of TwentiethCentury Music, Englewood Cliffs, New Jersey, Prentice-Hall, pp. 208-269. 
Broft, R.D. and Pryke, $S$ 